\title{
A comfortable attachment for a thermistor respiration transducer
}

\author{
MARTIN OLDMAN \\ The Institute of Sound and Vibration Research, The University, Southampton, England S09 5NH
}

\begin{abstract}
The construction of a simple thermistor respiration-transducer support assembly, which allows the monitoring of respiration in human subjects without the discomfort often associated with more traditional attachment methods, is described.
\end{abstract}

Although they are more selective than strainguage or mercury-in-rubber methods, the use of temperature-sensitive devices for monitoring respiration in human subjects can be uncomfortable for the subject due to the direct attachment of the transducer to the subject's nose (Brener, 1967). An example in popular use is the Grass nasal thermocouple (Type TCT 1R), attached to the nose by means of a plastic clip. This brief paper describes the construction of a thermistor support system which has been found to produce excellent results without causing the subject any discomfort over long periods of use. The construction further commends itself by being quickly and cheaply achieved. The components used and described below are readily available on the United Kingdom market, but the general design principles are applicable, using alternative components demanded by local supply conditions.

The system, shown in Figure 1, comprises a Type G23B thermistor (ITT Electronic Services) attached to a plastic spectacles frame (nasal bridge height of at least $6 \mathrm{~mm}$ ) from which the lenses have been removed. This particular thermistor has a resistance of $2 \mathrm{kohms}$ at $20^{\circ} \mathrm{C}$ and has proven very satisfactory. The bead has a partially flexible wire support which also forms one of the electrical connections to it. The support is constructed by tightly winding .7-mm-diam tinned copper wire onto a straight former of $1.6 \mathrm{~mm}$ diam until a coiled length of approximately $100 \mathrm{~mm}$ has been produced. The support is bent to the specified shape and stiffened along most of its upper length by the application of solder; the lower $5 \mathrm{~mm}$ is similarly treated. A second lead of fine, stranded $(10 \times .1 \mathrm{~mm})$ sleeved wire is passed through the coil and terminated at the upper end at one pole of a 1-mm twopole socket (Series SM, Pye Connectors Ltd.). The upper end of the coiled wire is connected to the second pole of the socket. The thermistor bead is then attached to the two exposed leads at the lower end, and the whole of the support system is covered with 3-mm PVC sleeving. The attachment of the thermistor support system to the nasal bridge of the spectacles frame can be achieved either by cementing with an appropriate bonding

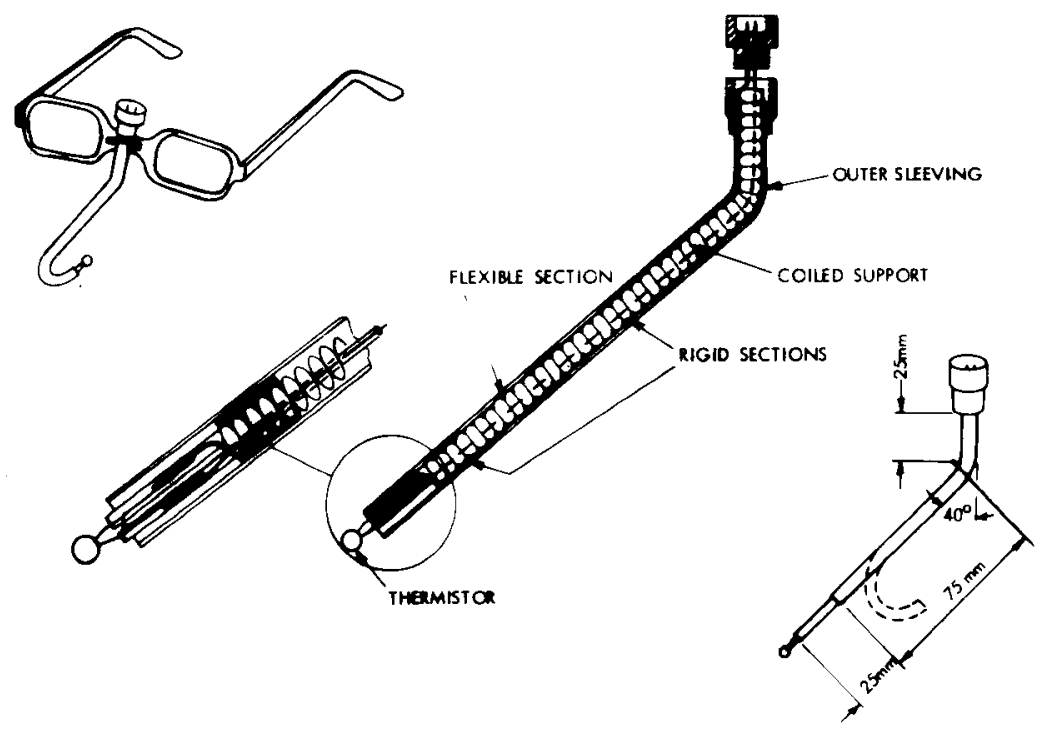

Figure 1. Construction details of thermistor support assembly. 
material or by bracketing. A mating plug is inserted into the socket which, by connecting to a suitable dc amplifier via a Wheatstone bridge circuit, completes the respiration monitoring system. By manipulating the flexible portions of the support assembly, the thermistor can be positioned beneath either of the subject's nostrils, and this placement will be maintained indefinitely.

The thermistor support assembly weighs only $7 \mathrm{~g}$ and can be worn for long periods without discomfort. Total construction time is less than $30 \mathrm{~min}$, and most of the required materials are drawn from common stock.

\section{REFERENCD}

BRENER, J. Heart rate. In P. H. Venables \& Irene Martin (Eds.), A manual of psychophysiological methods. Amsterdam: North-Holland, 1967.

(Received for publication March 9, 1976.) 